\title{
Nitric Oxide-Releasing S-Nitrosothiol-Modified Xerogels
}

\author{
Daniel A. Riccio ${ }^{1}$, Kevin P. Dobmeier ${ }^{1}$, Evan M. Hetrick, Benjamin J. Privett, Heather S. \\ Paul, and Mark H. Schoenfisch* \\ Department of Chemistry, University of North Carolina, Chapel Hill, NC 27599, USA
}

\section{Abstract}

The synthesis, material characterization, and in vitro biocompatibility of $S$-nitrosothiol (RSNO)modified xerogels is described. Thiol-functionalized xerogel films were formed by hydrolysis and co-condensation of 3-mercaptopropyltrimethoxysilane (MPTMS) and methyltrimethoxysilane (MTMOS) sol-gel precursors at varying concentrations. Subsequent thiol nitrosation via acidified nitrite produced RSNO-modified xerogels capable of generating nitric oxide (NO) for up to 2 weeks under physiological conditions. Xerogels also exhibited NO generation upon irradiation with broadspectrum light or exposure to copper, with NO fluxes proportional to wattage and concentration,

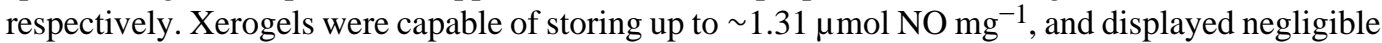
fragmentation over a 2 week period. Platelet and bacterial adhesion to nitrosated films was reduced compared to non-nitrosated controls, confirming the antithrombotic and antibacterial properties of the NO-releasing materials. Fibroblast cell viability was maintained on the xerogel surfaces illustrating the promise of RSNO-modified xerogels as biomedical device coatings.

\section{Introduction}

\begin{abstract}
Sustaining a functional interface for indwelling medical devices in their working environment (e.g., blood, tissue, etc.) remains a significant challenge. Blood-contacting devices such as stents and intravascular sensors suffer from impaired function due to platelet adhesion and aggregation [1-3]. Tissue-based devices are sequestered from the surrounding tissue by a dense collagen capsule due to the foreign body response [4,5]. Isolation of these devices often render them useless and hinder wound healing. All implanted medical devices also increase the risk of infection due to bacterial surface contamination. Indeed, indwelling medical devices are responsible for $>1,000,000$ hospital acquired infections per year in the U.S. alone [6].
\end{abstract}

Strategies to actively combat these issues include device coatings that release antithrombotic or antimicrobial agents (e.g., heparin and silver ions) and have become an important area of study $[7,8]$. Surface generation of nitric oxide (NO), a free-radical active in many physiological processes including platelet activation, angiogenesis, vasodilation, wound healing, and host defense against infection represents a powerful technique with the potential to alleviate many of the problems affecting indwelling medical devices today [9-13]. Materials modified with NO-releasing polymer coatings have proven effective at reducing both bacterial and platelet adhesion in vitro [14,15], inhibiting in vivo infection [16], and facilitating tissue integration of the implants [17].

(C) 2009 Elsevier Ltd. All rights reserved.

*Corresponding author. mhs@unc.edu.

${ }^{1}$ D.A.R. and K.P.D. contributed equally to this work.

Publisher's Disclaimer: This is a PDF file of an unedited manuscript that has been accepted for publication. As a service to our customers we are providing this early version of the manuscript. The manuscript will undergo copyediting, typesetting, and review of the resulting proof before it is published in its final citable form. Please note that during the production process errors may be discovered which could affect the content, and all legal disclaimers that apply to the journal pertain. 
Due to its reactive nature, $\mathrm{NO}$ donors or functional groups that store and release NO have been widely developed and include nitrosamines, organic nitrates, metal-NO complexes, $N$ diazeniumdiolates, and $S$-nitrosothiols (RSNOs) $[18,19]$. As compounds that are formed endogenously via the nitrosation of free thiols by reactive nitrogen species (e.g., $\mathrm{N}_{2} \mathrm{O}_{3}$ ) [20], RSNOs are a particularly promising class of NO donor for in vivo applications. Endogenous RSNOs, such as $S$-nitrosoalbumin and $S$-nitrosoglutathione (GSNO), act as biological transporters of NO in the blood stream [11]. As such, concerns regarding the formation of potentially toxic by-products are minimal compared to other donor systems (e.g., $\mathrm{N}$ diazeniumdiolates).

Small molecule RSNOs such as $S$-nitroso- $N$-acetyl-L-cysteine (SNAC), $S$-nitroso- $N$-acetylDL-penicillamine (SNAP), and GSNO have been widely studied as NO delivery agents with well documented antimicrobial [21] and antithrombotic [22-24] effects. Incorporation of RSNOs into polymers may extend the utility of these NO donors to applications such as device coatings, thus providing NO release at a device/tissue (or blood) interface. Despite the potential benefits of RSNOs, reports of RSNO-modified polymeric coatings for NO generation are limited. Bohl and West reported the formation of $S$-nitrosocysteine-modified polyethylene glycol (PEG) hydrogels capable of generating NO for short periods (4-12 h) [25]. These polymers reduced smooth muscle cell adhesion on sections of angioplasty-damaged arteries in rat models [26]. The synthesis of NO-releasing polymers consisting of small molecule RSNOs such as SNAC and GSNO dispersed in PEG or solid poly(vinyl alcohol)/poly(vinyl pyrrolidone) films was reported by de Oliveira and co-workers [27-30]. The NO delivery was accomplished by rapid leaching of the hydrophilic small-molecule RSNO from the polymer into the soak media. Frost and Meyerhoff described photo-switchable NO-generating materials via RSNO-modified fumed silica particles doped into silicone rubber polymers [31]. Light was required to liberate NO from these interfaces (NO fluxes $\geq 1.7 \mathrm{pmol} \mathrm{cm}^{-2} \mathrm{~s}^{-1}$ for nearly $12 \mathrm{~h}$ with $40 \mathrm{~W}$ illumination). Seabra et al. reported on polynitrosated polyesters with covalently attached RSNO functionalities capable of significant initial NO release levels $\left(475 \mu \mathrm{mol} \mathrm{g}{ }^{-1}\right.$ $\mathrm{h}^{-1}$ for $2 \mathrm{~h}$ ) at physiological temperature [32]. However, the polyester macromolecules were water-insoluble liquids best suited for transdermal NO delivery. To date, the above methods have not been proven useful as coatings for indwelling medical devices due to limited NO release durations and/or leaching of the NO donor.

Herein, we describe the use of sol-gel chemistry [33] to form RSNO-modified xerogels as biocompatible NO-releasing coatings. Both the NO release, as a function of multiple NO release triggers, and the stability of nitrosated 3-mercaptopropyltrimethoxysilane-derived films are evaluated. The ability of such coatings to resist bacterial and platelet adhesion, and their effect on fibroblast viability are examined.

\section{Materials and Methods}

3-Mercaptopropyltrimethoxysilane (MPTMS), ethyltrimethoxysilane (ETMOS), and isobutyltrimethoxysilane (BTMOS) were purchased from Gelest (Tullytown, PA). Methyltrimethoxysilane (MTMOS) and diethylenetriamine pentaacetic acid (DTPA) were purchased from Fluka (Buchs, Switzerland). Pseudomonas aeruginosa (ATCC \#19143) was obtained from American Type Culture Collection (Manassas, VA). Nitric oxide calibration gas (25.7 ppm; balance $\mathrm{N}_{2}$ ) was purchased from National Welders Supply Co. (Durham, NC). Type A19 60 and $100 \mathrm{~W}$ General Electric and type A21 $200 \mathrm{~W}$ Sylvania incandescent light bulbs were purchased from Lowe's (Chapel Hill, NC). Whole blood was obtained from healthy pigs at the Francis Owen Blood Research Laboratory (Chapel Hill, NC). Fetal bovine serum (FBS), penicillin/streptomycin (P/S) and trypsin were obtained from Sigma (St. Louis, MO). Eagles minimal essential medium (MEM) was purchased from Gibco (Carlsbad, CA). Phosphate buffered saline (PBS) used for cell culture experiments was prepared and maintained 
in a sterile environment. L929 mouse fibroblasts (ATCC \#CCL-1) were purchased from the University of North Carolina Tissue Culture Facility (Chapel Hill, NC). The MTT reagent 3(4,5-dimethylthiazol-2-yl)-2,5-diphenyltetrazolium bromide (MTT) and dimethyl sulfoxide (DMSO) used in the MTT assay were purchased from Fisher Scientific (St. Louis, MO). Other solvents and chemicals were analytical-reagent grade and used as received. Distilled water was purified to $18.2 \mathrm{M} \Omega \cdot \mathrm{cm}$ with a Millipore Milli-Q Gradient A-10 water purification system (Bedford, MA).

\subsection{Xerogel Film Synthesis}

Xerogel coatings were prepared as follows. Sols containing 20-80\% (v:v total silane) MPTMS (balance MTMOS) were created by shaking ethanol $(800 \mu \mathrm{L})$, MTMOS $(160-640 \mu \mathrm{L})$, MPTMS $(640-160 \mu \mathrm{L}$; total silane volume $=800 \mu \mathrm{L})$, and $0.5 \mathrm{M} \mathrm{HCl}(25 \mu \mathrm{l})$ for $1 \mathrm{~h}$. After allowing the sols to age under ambient conditions for an additional $4 \mathrm{~h}, 30 \mu \mathrm{l}$ aliquots were cast onto $9 \times 25 \mathrm{~mm}^{2}$ precleaned glass substrates. All substrates were sonicated in ethanol for 20 min and dried under $\mathrm{N}_{2}$. Substrates for the 20-60\% MPTMS films, were ozone (UV) cleaned for $20 \mathrm{~min}$ in a BioForce TipCleaner (Ames, IA). Substrates for the 80\% MPTMS films, were soaked in $10 \%(\mathrm{v} / \mathrm{v})$ nitric acid for $30 \mathrm{~min}$ at $80^{\circ} \mathrm{C}$, rinsed with distilled water, and dried under $\mathrm{N}_{2}$. After casting of the sol, all physisorbed films were allowed to dry at room temperature overnight, and then transferred to a $70{ }^{\circ} \mathrm{C}$ oven for $2 \mathrm{~d}$.

\subsection{Nitrosothiol Formation}

Thiols of MPTMS/MTMOS xerogels were nitrosated by reaction with acidified nitrite [34]. Films were protected from light and incubated for fixed intervals in $0.5 \mathrm{M} \mathrm{HCl}(2 \mathrm{~mL})$ containing a 10-fold molar excess of $\mathrm{NaNO}_{2}$ (vs. moles thiol) and $100 \mu \mathrm{M}$ DTPA. The xerogels were washed with $100 \mu \mathrm{M}$ DTPA and stored in the dark at $-20^{\circ} \mathrm{C}$ until use. Spectral characterization of RSNO formation was performed by affixing the slides normal to the light path of a PerkinElmer Lambda $40 \mathrm{UV} /$ Vis Spectrophotometer (Norwalk, CT) in cuvettes containing $2 \mathrm{~mL}$ phosphate buffered saline (PBS; 10mM phosphate, $\mathrm{pH}$ 7.4). Characteristic RSNO absorbance bands (330-350 nm; $\mathrm{n}_{0} \rightarrow \pi^{*}$ and $550-600 \mathrm{~nm} ; \mathrm{n}_{\mathrm{N}} \rightarrow \pi^{*}$ ) [35,36] were monitored as a function of nitrosation reaction time and concentration of mercaptosilane in the xerogel. Resulting spectra were normalized to the corresponding pathlength (i.e., average film thickness) of each xerogel composition. In addition, each xerogel composition's absorbance at $650 \mathrm{~nm}$ was baseline subtracted from their respective spectrum to control for background absorbance of the xerogel.

\subsection{Characterization of NO Release}

Nitric oxide release from RSNO-modified xerogels was monitored in $1 \mathrm{~s}$ intervals using a Sievers model 280i chemiluminescence nitric oxide analyzer (Boulder, CO). Calibration of the instrument was performed prior to each experiment using $25.7 \mathrm{ppm} \mathrm{NO}$ gas (balance $\mathrm{N}_{2}$ ) and air passed through a Sievers NO zero filter. Individual slides were immersed in $25 \mathrm{~mL}$ PBS containing $100 \mu \mathrm{M}$ DTPA and sparged with a $200 \mathrm{~mL} / \mathrm{min} \mathrm{N}_{2}$ stream. Temperature was maintained via a water bath at 0 or $37^{\circ} \mathrm{C}$. Light-initiated NO release was examined by employing incandescent bulbs of various wattages placed 6 inches above the sample flask. Copper-initiated release was studied by immersing the slides into $25 \mathrm{~mL}$ solutions of 10 and $25 \mu \mathrm{M} \mathrm{CuBr}_{2}$ in PBS. The sample flask was shielded from light with aluminum foil when light was not the intended initiator of NO release.

\subsection{Xerogel Film Stability}

Nitrosated xerogel films on glass slides $(\mathrm{n}=5)$ were immersed in $10 \mathrm{~mL}$ PBS and incubated at $37{ }^{\circ} \mathrm{C}$. Films were removed and transferred to fresh solutions of PBS at fixed intervals. Silicon (Si) concentrations in the PBS soak solutions were determined using a direct current 
plasma optical emission spectrometer (DCP-OES; ARL-Fisons Spectraspan 7; Beverly, MA) calibrated with 0-50 ppm Si standard solutions in PBS.

\subsection{Contact Angle Measurements}

Static water contact angle measurements of control and RSNO-modified xerogels were acquired with a KSV Instruments Cam 200 Optical Contact Angle Meter (Helsinki, Finland).

\subsection{Film Thickness Measurements}

Film thickness of the RSNO-modified xerogels was measured with a Tencor Alpha-Step 200 Profilometer (San Jose, CA). Half of the RSNO-modified xerogel coating was removed from the glass substrate and the interface was probed to acquire the film thickness.

\subsection{Bacterial Adhesion to RSNO Xerogels}

P. aeruginosa was cultured at $37^{\circ} \mathrm{C}$ in tryptic soy broth (TSB), pelleted by centrifugation, resuspended in $15 \%$ glycerol (v:v in PBS), and stored at $-80^{\circ} \mathrm{C}$. Cultures for bacterial adhesion studies were grown from a $-80^{\circ} \mathrm{C}$ stock in $37^{\circ} \mathrm{C}$ TSB overnight. A $1 \mathrm{~mL}$ aliquot of overnight culture was inoculated into $100 \mathrm{~mL}$ fresh TSB, incubated at $37^{\circ} \mathrm{C}$ with rotation, and grown to a concentration of $\sim 10^{8}$ colony-forming units (cfu) $/ \mathrm{mL}$ (verified by 10 -fold serial dilutions in PBS, plating on tryptic soy agar nutrient plates, and subsequent cfu enumeration). The bacteria were pelleted by centrifugation, rinsed with ultrapure water, and resuspended in sterile PBS. Control and RSNO-modified xerogels were immersed in 4-mL aliquots of bacterial suspension and incubated at $37^{\circ} \mathrm{C}$. After $1 \mathrm{~h}$, the xerogel substrates were removed from the bacterial suspension, gently immersed in ultrapure water to remove loosely-adhered cells, and dried under a stream of $\mathrm{N}_{2}$. To quantify bacterial adhesion, substrates were imaged in phase-contrast mode using a Zeiss Axiovert 200 inverted optical microscope (Chester, VA) at 20x magnification. Digital micrographs were captured with a Zeiss Axiocam digital camera (Chester, VA). To determine the percent surface coverage of bacteria, each image was digitally processed by applying a threshold value to differentiate adhered cells from the background. The number of pixels corresponding to adhered bacterial cells was digitally enumerated and the extent of bacterial adhesion reported as the percent of the xerogel substrate surface covered with bacterial cells.

\subsection{Platelet Adhesion to RSNO Xerogels}

Porcine blood from healthy pigs was drawn into acid citrate dextrose (ACD) anticoagulant (1 part ACD to 9 parts whole blood). Within 30 min of collection, samples were centrifuged at $200 \mathrm{~g}$ for $30 \mathrm{~min}$ at room temperature to obtain platelet rich plasma (PRP). To restore normal platelet activity, calcium chloride $\left(\mathrm{CaCl}_{2}\right)$ was added to the PRP supernatant to a final concentration of $0.5 \mathrm{mM} \mathrm{Ca}^{2+}$ while incubating the PRP for $5 \mathrm{~min}$ at $37^{\circ} \mathrm{C}$ [37]. For platelet adhesion studies, control and RSNO-modified xerogels were immersed in PRP for $1 \mathrm{hr}$ at 37 ${ }^{\circ} \mathrm{C}$. The slides were then dip-rinsed in Tyrode's buffer $(137 \mathrm{mM} \mathrm{NaCl}, 2.7 \mathrm{mM} \mathrm{KCl}, 5.6 \mathrm{mM}$ glucose, $\left.3.3 \mathrm{mM} \mathrm{KH}_{2} \mathrm{PO}_{4}, \mathrm{pH} 7.35\right)$ to remove loosely adhered platelets and immersed in $1 \%$ glutaraldehyde (v/v, Tyrode's buffer) to fix adherent cells. To preserve cell morphology, the slides were rinsed with Tyrode's buffer and Milli-Q purified water and then chemically dried by immersion in 50\%, 75\%, and 95\% ethanol (v/v, balance water) for $5 \mathrm{~min}, 100 \%$ ethanol for $10 \mathrm{~min}$, and hexamethyldisilazane overnight [38]. After solvent evaporation, films were sputtered with an $\mathrm{Au} / \mathrm{Pd}$ alloy and examined for platelet adhesion and morphology using a Hitachi S-4700 scanning electron microscope (SEM) at a working distance of $12 \mathrm{~mm}$ and a magnification of 1100x. Activated platelets were defined as exhibiting a dendritic or fully spread morphology. The number of adhered activated platelets was physically counted from the images. 


\subsection{Fibroblast Viability on RSNO-Modified Xerogels}

L929 mouse fibroblasts were grown to subconfluency in media (MEM with 10\% FBS, 20 U/ $\mathrm{mL}$ penicillin and $20 \mu \mathrm{g} / \mathrm{mL}$ streptomycin) at $37{ }^{\circ} \mathrm{C}$ and $5 \% \mathrm{CO}_{2}$. Cells were then trypsinized and resuspended in media at a concentration of $2 \times 10^{5}$ cells $/ \mathrm{mL}$. Xerogels were cast in 96well microplates, nitrosated via acidified nitrite, and rinsed thrice with sterile $100 \mu \mathrm{M}$ DTPA. Control and RSNO-modified xerogels were then incubated for $24 \mathrm{~h}$ with the fibroblast suspension $\left(200 \mu \mathrm{L}\right.$ per well) at $37{ }^{\circ} \mathrm{C}$ and $5 \% \mathrm{CO}_{2}$. After $24 \mathrm{~h}$, a MTT viability assay was carried out [39]. Briefly, $40 \mu \mathrm{L}$ of a $1 \mathrm{mg} / \mathrm{mL}$ MTT solution in sterile PBS was added to each well and incubated for $3 \mathrm{~h}$, after which all solution was removed from the well and $100 \mu \mathrm{L}$ DMSO was added to solubilize remaining crystals. The solution was then removed from the wells and added to fresh plates before analysis. In this way the absorbance measured at 570 $\mathrm{nm}$ was proportional to the concentration of viable cells in each well and not affected by any absorbance from the xerogel. Fibroblast viability on RSNO-modified and control xerogels was reported relative to the viability of fibroblasts on uncoated polystyrene wells at $24 \mathrm{~h}$. Data are expressed as mean value \pm standard deviation $(n \geq 8)$. Statistical significance was tested using a single factor ANOVA test $(\alpha=0.05)$.

\section{Results and Discussion}

\subsection{Xerogel Synthesis and Characterization}

The relative ease of xerogel modification using alkoxysilane and organosilane precursors makes sol-gel chemistry a convenient scaffold to prepare and fabricate NO-releasing materials and devices [40]. In these experiments, 3-mercaptopropyltrimethoxysilane (MPTMS), a commercially available thiol-terminated alkoxysilane, was hydrolyzed and co-condensed with one of three backbone alkylalkoxysilanes: methyltrimethoxysilane (MTMOS), ethyltrimethoxysilane (ETMOS), and isobutyltrimethoxysilane (BTMOS). Covalent incorporation of alkylalkoxysilanes into the siloxane network as inert polymer backbone materials facilitates control over the NO flux generated by the material and enhances xerogel stability [41]. While all sols appeared to form homogenous gels, curing of xerogel films formed with the bulky ETMOS and BTMOS alkylalkoxysilanes required prohibitively long periods, most likely due to the decreased rates of hydrolysis of sterically hindered alkoxysilanes [33]. After overnight aging of the sol, films cast from these materials and stored in a $70{ }^{\circ} \mathrm{C}$ oven for $>2$ weeks remained viscous and tacky. Conversely, films of MPTMS/MTMOS sols aged $4 \mathrm{~h}$ solidified overnight under ambient conditions, forming clear, rigid films when dried for $2 \mathrm{~d}$ at $70{ }^{\circ} \mathrm{C}$. Methyltrimethoxysilane was thus selected as the backbone alkoxysilane in all further experiments. Sols synthesized with $\geq 80 \%$ MPTMS exhibited uneven coating of glass substrates, which led to irreproducible surface areas. To remedy this, glass slides were soaked in a $10 \%$ (v:v) nitric acid solution at $80^{\circ} \mathrm{C}$ for 30 min prior to coating to promote siloxane formation between the silanes and silanols inherent to the glass surface, thus enhancing adsorption of the coating with the possibility of covalent bond formation.

Indeed, the acid treatment led to uniform and reproducible 80\% MPTMS xerogel coatings. Films formed with $100 \%$ did not uniformly coat the glass even with nitric acid treatment. The thickness of each composition of resulting xerogel was measured using profilometry. Upon increasing the MPTMS concentration from 20-80\% (v:v total silane, balance MTMOS), the average thickness increased from $14.22 \pm 2.64$ to $35.01 \pm 8.62 \mu \mathrm{m}$. Resulting xerogels were weighed and found to have average masses of $10.33 \pm 0.61,11.37 \pm 0.55,13.90 \pm 0.70$, and $10.63 \pm 0.68 \mathrm{mg}$ for $20,40,60$, and $80 \%$ MPTMS compositions, respectively. Although masses were relatively constant for all xerogels formed, the relative thicknesses increased with larger amounts of MPTMS. Xerogels with greater MTMOS character formed thinner films due to closer packing of the methyl group compared to the bulkier mercaptopropyl group. 
To establish conditions for optimal RSNO formation in the xerogel, films were prepared using $20-80 \%$ (v:v) MPTMS (balance MTMOS). Nitrosation of the primary thiol of MPTMS was carried out by immersing cured xerogel films in a solution of acidified nitrite containing 100 $\mu$ M DTPA to reduce catalytic RSNO decomposition by adventitious copper ions. Reaction of the pendant thiols of the xerogel network with nitrous acid resulted in $S$-nitrosothiol formation (Eq. 1) [36] with a concomitant color shift of the transparent xerogel film to a deep pink hue.

$$
\mathrm{RSH}+\mathrm{HNO}_{2} \rightleftarrows \mathrm{RSNO}+\mathrm{H}_{2} \mathrm{O}
$$

The characteristic UV and visible absorbance maxima of the S-NO bond (at 336 and $545 \mathrm{~nm}$, respectively) were monitored as a measure of the extent of thiol nitrosation. After $3 \mathrm{~h} \mathrm{immersion}$ in acidified nitrite, no further absorbance increases in the films were observed, indicating maximal RSNO formation (data not shown). Extended soaking periods up to $24 \mathrm{~h}$ resulted in a slight overall decrease in measured absorbance, which was attributed to partial thermal decomposition of the RSNOs. As shown in Figure 1, increasing the concentration of MPTMS in the xerogel films resulted in an increased overall absorbance after nitrosation. The observed pink color was also darker indicating greater RSNO formation for the more heavily thiolfunctionalized films. The color shift associated with nitrosation is thus a useful indication of the concentration of RSNOs (and hence NO-release potential) in the xerogel films.

The long-term stability of RSNO-modified xerogels in $37^{\circ} \mathrm{C}$ PBS solution was monitored by monitoring siloxane network degradation via elemental analysis of Si in PBS soak solutions. The xerogels films were stable in PBS. Solution in which 20-80\% MPTMS/MTMOS films had been soaked for 2 weeks showed negligible levels of xerogel fragmentation $(<0.5 \mathrm{ppm})$. In fact, the $\mathrm{Si}$ in the xerogel soak solutions was reduced compared to controls containing only bare glass substrates, ostensibly due to masking of $\sim 50 \%$ of the glass surface by the xerogel films.

\subsection{NO-Release Characterization of RSNO-Modified Xerogels}

$S$-Nitrosothiols exhibit a multitude of decomposition triggers [36]. Irradiation of RSNOs at either of their two absorption maxima (i.e., 330-350 and 550-600 nm) results in homolytic cleavage of the $\mathrm{S}-\mathrm{N}$ bond and generation of $\mathrm{NO}$ and a thiyl radical. The thiyl radical can trigger NO release via reaction with an additional RSNO molecule to produce a second equivalent of NO and the corresponding disulfide [36].

Photo-initiated NO-release from RSNO-modified xerogels was measured via chemiluminesence as a real-time flux from individual films immersed in $100 \mu \mathrm{M}$ DTPA (pH 7.4 PBS). The xerogels were irradiated using broadband, white light of varying intensity while the temperature of the sample flask was maintained at $0{ }^{\circ} \mathrm{C}$ to distinguish photo-initiation from thermal NO release. Films exhibited a characteristic on/off behavior of NO production when either irradiated by light or enclosed in the dark, respectively (Fig. 2A). Xerogels were also found to have pronounced increases in NO flux upon exposure to higher light intensities (Fig. 2B). Of note, the inset of Figure 2B details the flux of an RSNO-modified xerogel without the presence of light and at $0{ }^{\circ} \mathrm{C}$. Although the thermal decomposition is hindered, it is still observed at $0{ }^{\circ} \mathrm{C}$ as demonstrated by a non-zero baseline in Figure $2 \mathrm{~A}$ when the film was shielded from light.

The rapid kinetics of NO release from these films in the presence of a $200 \mathrm{~W}$ light source indicates that photo-initiation is an efficient means to quantify the amount of NO stored in the xerogel network. To determine the total NO storage capacity of the xerogels, films were irradiated with a $200 \mathrm{~W}$ light for periods of $16 \mathrm{~h}$. The total amount of stored NO scaled proportionally with the amount of incorporated MPTMS in the xerogels, ranging from $0.47 \pm$ 
0.13 to $1.31 \pm 0.07 \mu \mathrm{mol} \mathrm{mg}^{-1}$ (Table 1 ). Films examined after exposure to the light for $16 \mathrm{~h}$ lacked any remaining pinkish hue, providing a visual indication that all stored NO had indeed been released, as corroborated by a return to baseline on the chemiluminescent $\mathrm{NO}$ analyzer.

Catalytic reaction of RSNOs with $\mathrm{Cu}(\mathrm{I})$, commonly generated from the reduction of added or adventitious $\mathrm{Cu}$ (II) via trace thiolate ion, results in NO production [42]. Thus, the use of copper as a trigger to generate $\mathrm{NO}$ from RSNOs has been reported on extensively in the literature $[18,36,43]$. The extent of copper-induced NO generation from RSNO-modified xerogels was examined by immersing xerogel films in various concentrations of copper bromide. Assays were performed with the $\mathrm{Cu}$ (II) compound opposed to $\mathrm{Cu}(\mathrm{I})$ because of the general waterinsolubility of $\mathrm{Cu}(\mathrm{I})$ compounds [44]. As shown in Figure 3, xerogels exhibited a NO flux dependance on copper concentration with the greatest NO flux $\left(\sim 26 \mathrm{pmol} \mathrm{cm}^{-2} \mathrm{~s}^{-1}\right)$ observed at $25 \mu \mathrm{M} \mathrm{CuBr}_{2}$, the largest concentration that we investigated. Since most copper in the body is bound to proteins and peptides for transport and homeostasis [44], the relevance of this concentration remains questionable. The concentration of "free" copper, or loosely bound hydrated $\mathrm{Cu}(\mathrm{I})$ and $\mathrm{Cu}(\mathrm{II})$ complexes, in serum is approximately $1.6 \mu \mathrm{M}$ [45] and less than a single atom per cell intracellularly [46,47]. Dicks and Williams reported that $\mathrm{Cu}(\mathrm{II})$ complexed to amino acids, tripeptides, human serum albumin, and ceruloplasmin decomposes RSNOs to generate $\mathrm{NO}$ upon reduction to $\mathrm{Cu}(\mathrm{I})$, indicating a potential for copper-initiated NO release in vivo [48]. However, the same authors concluded that although the tightly bound forms of $\mathrm{Cu}$ (II) can generate $\mathrm{NO}$ from RSNOs, the NO release kinetics are decreased when compared to that initiated by "free" copper. Unfortunately, a model for elucidating plausible physiological NO fluxes due to copper-initiated RSNO decomposition remains incomplete.

Thermal RSNO decomposition represents the most plausible trigger of NO release from RSNO-modified xerogels employed as biomedical implant coatings. To model this pathway, xerogel films were immersed in $25 \mathrm{~mL}$ of $100 \mu \mathrm{M}$ DTPA (pH $7.4 \mathrm{PBS}$ ), maintained at $37^{\circ} \mathrm{C}$, and shielded from ambient light. As shown in Figure 4, NO fluxes were monitored for 2 weeks under these conditions. Although the amount of MPTMS in each film differed, all xerogels exhibited similar initial fluxes of $\mathrm{NO}$ at $37^{\circ} \mathrm{C}$. Experiments are currently underway to probe this behavior further. After the initial maximum flux of NO subsided, the xerogels exhibited NO fluxes dependant on their MPTMS concentrations (Fig. 4A). After $24 \mathrm{~h}$, the NO fluxes of all films dropped significantly lower, but remained measurable up to 2 weeks (Fig. 4B).

Previous work has deduced that a NO flux of $0.4 \mathrm{pmol} \mathrm{cm}^{-2} \mathrm{~s}^{-1}$ is necessary to reduce platelet adhesion to surfaces [49]. The 20\% MPTMS xerogel demonstrated a flux above this threshold for up to $3 \mathrm{~d}$, while the 40-80\% MPTMS xerogel compositions released at or above this level for periods of up to 1-2 weeks. Likewise, NO fluxes $>35 \mathrm{pmol} \mathrm{cm}^{-2} \mathrm{~s}^{-1}$ have been reported to reduce $P$. aeruginosa adhesion to surfaces [50]. RSNO-modified xerogels exhibited initial maximum NO fluxes of $\sim 600 \mathrm{pmol} \mathrm{cm}^{-2} \mathrm{~s}^{-1}$, an order of magnitude larger than the reported threshold and thus large enough to resist bacterial adhesion during the critical phase soon after device implantation [7]. Hetrick et al. also reported that the delivery of $1.35 \mu \mathrm{mol}$ of NO per $\mathrm{cm}^{2}$ of implant surface area reduced the thickness of collagen encapsulation at the site of a subcutaneous implant by $\geq 50 \%$ compared to controls [17]. Each of the RSNO-modified xerogel compositions reported herein was capable of storing at least $2.35 \mu \mathrm{mol} \mathrm{cm}{ }^{-2}$, well in excess of that required to reduce encapsulation in vivo. The total amount of NO stored coupled with physiologically relevant fluxes, highlight RSNO-modified xerogels as candidate coatings for improving the biocompatibility of indwelling medical devices. Further studies focusing on the anti-bacterial and anti-platelet properties of the xerogels were thus conducted.

\subsection{Antibacterial Properties of RSNO-Modified Xerogels}

To assess the antibacterial properties of RSNO-modified xerogel films, controls and NOreleasing substrates were incubated for $1 \mathrm{~h}$ in a suspension of $P$. aeruginosa $\left(10^{8} \mathrm{CFU} / \mathrm{mL}\right)$ in 
PBS. After removal from the bacterial suspension, the extent of bacterial adhesion to substrates was determined using phase contrast optical microscopy. As shown in Figure 5, a significant reduction in bacterial adhesion was observed at NO-releasing xerogels compared to controls, an observation consistent with the findings of previous studies [14,50-53]. Specifically, $P$. aeruginos $a$ adhesion was reduced by 73,79,77, and 93\% at RSNO-modified 20, 40, 60, and $80 \%$ MPTMS/MTMOS xerogels, respectively, compared to controls with identical mercaptosilane content. From a clinical perspective, these results are promising as the reduction of initial bacterial adhesion is often regarded as the most critical step for preventing infection related to indwelling medical devices [7,54,55]. It is also likely that the continued NO release from RSNO-modified xerogels may exert beneficial long-term antibacterial and woundhealing properties in vivo [16]. Studies to assess the antibacterial properties of RSNO-modified xerogels in an animal model are currently underway.

As shown in Figure 5, bacterial adhesion to controls (non-nitrosated xerogels) decreased with increasing thiol concentration. Indeed, a $38 \%$ reduction in $P$. aeruginosa surface coverage was observed for controls as the thiol concentration within the xerogel increased from 20 to $80 \%$ (v:v). Previous work suggests that such reduced bacterial adhesion may be the result of altered surface hydrophilicity and the hydrophobic effect known to mediate bacterial adhesion [5658]. To understand the influence of thiol concentration on surface hydrophobicity, static water contact angles were measured at both nitrosated and control xerogels. As shown in Table 2, the water contact angle of control xerogels decreased from 77 to $48^{\circ}$ as the concentration of MPTMS within the xerogel was increased from 20 to $80 \%$ (v:v total silane, balance MTMOS). Analogous behavior was observed for RSNO-modified xerogels indicating that more hydrophilic surfaces are formed with increasing thiol concentration for both control and RSNOmodified MPTMS/MTMOS xerogels, likely resulting in reduced hydrophobic interaction between bacterial cells and the surface. Of note, the water contact angle of nitrosated xerogels was consistently lower (i.e., more hydrophilic) than non-nitrosated controls of the same thiol concentration. However, this difference in surface hydrophobicity alone does not account for the full reduction in bacterial adhesion. For example, the contact angle of both control $60 \%$ MPTMS and NO-releasing 40\% MPTMS was $58^{\circ}$. However, 30\% bacterial surface coverage was observed at control $60 \%$ MPTMS, while the surface coverage at NO-releasing $40 \%$ MPTMS xerogels was only $8 \%$. While both surfaces were characterized by identical water contact angles, the NO-releasing surface had $73 \%$ less bacterial adhesion, indicating that it is primarily NO release (and not surface hydrophobicity) that dictates the extent of bacterial adhesion to these materials.

\subsection{Antithrombotic Properties of RSNO-Modified Xerogels}

The degree of activation of surface-adhered platelets is crucial in determining the hemocompatibility of a material [59]. As platelets become activated, morphological changes occur shifting the geometry of a platelet from a native discoid shape to dendritic (i.e., exhibiting pseudopodia) and ultimately fully spread conformations [60]. The effect of RSNO-modified xerogels on platelet activation and adhesion was examined by exposing 20-80\% MPTMS xerogel films to platelet-rich porcine plasma for $1 \mathrm{~h}$. Scanning electron microscopy (SEM) was used to probe the morphological state of adhered platelets. Table 3 illustrates the observed reductions of activated platelets at RSNO-modified surfaces compared to control xerogels. Representative SEM micrographs of platelet adhesion to xerogel surfaces are shown in Figure 6. The NO-release decreased the average activated platelet coverage on RSNO-modified films versus controls, as determined from the mean number of activated platelets. Although all compositions showed a reduction in the average number of activated adhered platelets versus corresponding controls, the 40 and 60\% MPTMS NO-releasing films were the only ones to exhibit statistically significant decreases (47 and 52\%, respectively) $(P \leq 0.05)$. The platelet activation for $20 \%$ MPTMS NO-releasing xerogels may be attributed to a lower NO flux 
generated by these materials ( $\leq 30 \mathrm{pmol} \mathrm{cm} \mathrm{s} \mathrm{s}^{-1}$ after $30 \mathrm{~min}$ ). The increased adhesion of activated platelets to $80 \%$ MPTMS NO-releasing xerogels versus NO-releasing xerogels with lower MPTMS concentration (i.e., 20-60\%) is attributed to the increased surface roughness of this composition, as evident in Figure 6. [61]. In vivo, minimum NO flux requirements are likely to increase due to rapid NO scavenging by other free radicals, thiols, and heme proteins in blood [62]. Nevertheless, the low thrombogenicity and extended NO-release durations for RSNO-modified xerogel coatings support the further investigation of these materials as thromboresistant coatings.

\subsection{Fibroblast Viability on RSNO-Modified Xerogels}

The methylthiazol tetrazolium (MTT) assay was employed to determine the general cytotoxicity of RSNO-modified xerogels to mammalian cells. The MTT assay is a quantitative colorimetric assay that measures the concentration of viable cells through the cleavage of a tetrazolium ring in active mitochondria, resulting in the production of a formazan that absorbs in solution at $570 \mathrm{~nm}$ [39]. Since the reaction occurs only in living cells, the optical density measured is directly related to the concentration of viable cells. The viability of L929 mouse fibroblasts on control and RSNO-modified 20-80\% MPTMS/MTMOS xerogels was compared to fibroblast viability on uncoated, sterile polystyrene (PS) wells (Fig. 7). Relative to uncoated PS wells, the fibroblast viability on control (non-nitrosated) xerogel surfaces after $24 \mathrm{~h}$ was $61.8-80.1 \%$. The reduced viability may be attributed to decreased cell adhesion on the hydrophilic thiol-terminated surfaces. As shown in Figure 7, the fibroblast viability was slightly less for the nitrosated (RSNO-modified) xerogels. At $24 \mathrm{~h}$, the relative viability was 42.0$58.6 \%$ that of PS for the NO-releasing xerogels. The initial decrease in fibroblast viability at RSNO-modified xerogels compared to controls coincides with the initial burst of NO released from the surface. Although NO's toxicity at elevated concentrations is well documented [63], given the anti-adhesion properties of RSNO-modified xerogels towards bacteria and platelets, it is possible NO release may prevent fibroblast adhesion to the xerogel surface, contributing to the decrease in viability observed.

Of note, the fibroblast viability at both the RSNO-modified and control 80\% MPTMS/MTMOS xerogel surfaces was different than that observed for other MPTMS concentrations. When the 80\% MPTMS xerogels were cast in the bottom of the PS 96-well plates, the sols did not appear to wet the surfaces as completely or uniformly as the other MPTMS compositions. Unlike the glass substrates, treatment with nitric acid did not remedy this problem. Such a drastic increase in viability at $80 \%$ MPTMS/MTMOS xerogels would be expected if a significant portion of the PS surface was left available for fibroblast adhesion. As the coating of certain medical devices is the intended application of these biomaterials, future work is planned to explore and optimize the adherence of the xerogel coatings to a range of medical-grade polymeric materials. Experiments to elucidate the effect of $\mathrm{NO}$ on fibroblast viability and adhesion in a dose dependent manner are also currently in progress.

\section{Conclusions}

Poor biocompatibility continues to plague many indwelling medical devices. Nitric oxide release at the device/tissue (or blood) interface has been shown to help overcome this problem via the reduction of platelet adhesion and activation, bacterial adhesion, and the foreign body response. We have developed $S$-nitrosothiol (RSNO)-modified xerogels as versatile NOreleasing coatings. Such NO-releasing coatings may mitigate toxicity concerns due to the endogenous nature of $S$-nitrosothiols and thus a decomposition pathway that mimics biologically-occurring processes. Nitric oxide levels ranging from 0.47 . \pm 0.13 to $1.31 \pm 0.07$ $\mu \mathrm{mol} \mathrm{mg}{ }^{-1}$ may be stored with tunable NO release via exposure to light, copper, and/or heat. Of relevance to future biomedical device applications, the materials were stable under 
physiologically-relevant conditions and released $\mathrm{NO}$ above previously determined threshholds required to reduce platelet and bacterial adhesion at surfaces for periods up to 2 weeks. Pronounced reduction in $P$. aeruginosa and activated platelet adhesion was observed for the RSNO-modified xerogels versus controls. Fibroblasts exposed to RSNO-modified xerogels remained viable, further suggesting the potential biomedical use of such coatings. Future in vivo studies will explore how these materials fare with regards to bacterial infection and wound healing.

\section{Acknowledgements}

This research was supported by the National Institutes of Health (NIH EB000708). K.P.D. gratefully acknowledges a National Science Foundation Graduate Research Fellowship. E.M.H. acknowledges financial support from the Pfizer Analytical Chemistry Graduate Research Fellowship. The authors thank the University of North Carolina at Chapel Hill Francis Owen Blood Research Laboratory for providing porcine blood samples. The authors also wish to thank the Channing J. Der Laboratory and Ellen V. Stevens for providing supplies and assistance in the fibroblast viability assays

\section{References}

1. Wisniewski N, Reichert M. Methods for reducing biosensor membrane biofouling. Colloids Surf, B 2000;18:197-219.

2. Frost MC, Meyerhoff ME. Implantable chemical sensors for real-time clinical monitoring: progress and challenges. Curr Opin Chem Biol 2002;6:633-641. [PubMed: 12413548]

3. Ratner BD. The catastrophe revisited: Blood compatibility in the 21 st century. Biomaterials 2007;28:5144-5147. [PubMed: 17689608]

4. Ratner BD. Reducing capsular thickness and enhancing angiogenesis around implant drug release systems. J Controlled Release 2002;78:211-218.

5. Ratner BD, Bryant SJ. Biomaterials: Where we have been and where we are going. Annu Rev Biomed Eng 2004;6:41-75. [PubMed: 15255762]

6. Darouiche RO. Treatment of infections associated with surgical implants. New Engl J Med 2004;350:1422-1429. [PubMed: 15070792]

7. Hetrick EM, Schoenfisch MH. Reducing implant-related infections: active release strategies. Chem Soc Rev 2006;35:780-789. [PubMed: 16936926]

8. Jordan SW, Chaikof EL. Novel thromboresistant materials. J Vasc Surg 2007;45104A-15A

9. Fang FC. Mechanisms of nitric oxide-related antimicrobial activity. J Clin Invest 1997;99:2818-2825. [PubMed: 9185502]

10. Ignarro LJ. Nitric oxide: A unique endogenous signaling molecule in vascular biology (Nobel lecture). Angew Chem Int Ed 1999;38:1882-1892.

11. Williams DLH. A chemist's view of the nitric oxide story. Org Biomol Chem 2003;1:441-449. [PubMed: 12926240]

12. Luo JD, Chen AF. Nitric oxide: a newly discovered function on wound healing. Acta Pharmacol Sin 2005;26:259-264. [PubMed: 15715920]

13. Wallis JP. Nitric oxide and blood: a review. Transfus Med 2005;15:1-11. [PubMed: 15713123]

14. Hetrick EM, Schoenfisch MH. Antibacterial nitric oxide-releasing xerogels: Cell viability and parallel plate flow cell adhesion studies. Biomaterials 2007;28:1948-1956. [PubMed: 17240444]

15. Wu YD, Zhou ZR, Meyerhoff ME. In vitro platelet adhesion on polymeric surfaces with varying fluxes of continuous nitric oxide release. J Biomed Mater Res, Part A 2007;81A:956-963.

16. Nablo BJ, Prichard HL, Butler RD, Klitzman B, Schoenfisch MH. Inhibition of implant-associated infections via nitric oxide. Biomaterials 2005;26:6984-6990. [PubMed: 15978663]

17. Hetrick EM, Prichard HL, Klitzman B, Schoenfisch MH. Reduced foreign body response at nitric oxide-releasing subcutaneous implants. Biomaterials 2007;28:4571-4580. [PubMed: 17681598]

18. Wang PG, Xian M, Tang XP, Wu XJ, Wen Z, Cai TW, et al. Nitric oxide donors: Chemical activities and biological applications. Chem Rev 2002;102:1091-1134. [PubMed: 11942788] 
19. Al-Sa'doni HH, Ferro A. Current status and future possibilities of nitric oxide-donor drugs: Focus on S-nitrosothiols. Mini-Rev Med Chem 2005;5:247-254. [PubMed: 15777259]

20. Hogg N. Biological chemistry and clinical potential of S-nitrosothiols. Free Radical Biol Med 2000;28:1478-1486. [PubMed: 10927172]

21. de Souza GFP, Yokoyama-Yasunaka JKU, Seabra AB, Miguel DC, de Oliveira MG, Uliana SRB. Leishmanicidal activity of primary S-nitrosothiols against Leishmania major and Leishmania amazonensis: Implications for the treatment of cutaneous leishmaniasis. Nitric Oxide-Biol Chem 2006;15:209-216.

22. Radomski MW, Rees DD, Dutra A, Moncada S. S-Nitroso-glutathione inhibits platelet activation in vitro and in vivo. Br J Pharmacol 1992;107:745-749. [PubMed: 1335336]

23. Langford EJ, Brown AS, Wainwright RJ, Debelder AJ, Thomas MR, Smith REA, et al. Inhibition of platelet activity by S-nitrosoglutathione during coronary angioplasty. Lancet 1994;344:1458-1460. [PubMed: 7526102]

24. Salas E, Moro MA, Askew S, Hodson HF, Butler AR, Radomski MW, et al. Comparative pharmacology of analogs of S-nitroso-N-acetyl-DL-penicillamine on human platelets. Br J Pharmacol 1994;112:1071-1076. [PubMed: 7524991]

25. Bohl KS, West JL. Nitric oxide-generating polymers reduce platelet adhesion and smooth muscle cell proliferation. Biomaterials 2000;21:2273-2278. [PubMed: 11026633]

26. Masters KSB, Lipke EA, Rice EEH, Liel MS, Myler HA, Zygourakis C, et al. Nitric oxide-generating hydrogels inhibit neointima formation. J Biomater Sci Polymer Ed 2005;16:659-672.

27. Shishido SM, de Oliveira MG. Polyethylene glycol matrix reduces the rates of photochemical and thermal release of nitric oxide from S-nitroso-N-acetylcysteine. Photochem Photobiol 2000;71:273280. [PubMed: 10732444]

28. Shishido SM, Seabra AB, Loh W, de Oliveira MG. Thermal and photochemical nitric oxide release from S-nitrosothiols incorporated in pluronic F127 gel: potential uses for local and controlled nitric oxide release. Biomaterials 2003;24:3543-3553. [PubMed: 12809783]

29. Seabra AB, Da Rocha LL, Eberlin MN, De Oliveira MG. Solid films of blended poly(vinyl alcohol)/ poly(vinyl pyrrolidone) for topical S-nitrosoglutathione and nitric oxide release. J Pharm Sci 2005;94:994-1003. [PubMed: 15793801]

30. Seabra AB, Pankotai E, Feher M, Somlai A, Kiss L, Biro L, et al. S-nitrosoglutathione-containing hydrogel increases dermal blood flow in streptozotocin-induced diabetic rats. Br J Dermatol 2007;156:814-818. [PubMed: 17263816]

31. Frost MC, Meyerhoff ME. Synthesis, characterization, and controlled nitric oxide release from Snitrosothiol-derivatized fumed silica polymer filler particles. J Biomed Mater Res, Part A 2005;72A: 409-419.

32. Seabra AB, da Silva R, de Oliveira MG. Polynitrosated polyesters: Preparation, characterization, and potential use for topical nitric oxide release. Biomacromolecules 2005;6:2512-2520. [PubMed: 16153087]

33. Brinker, J.; Scherer, G. New York: Academic Press, Inc; 1990. Sol-Gel Science.

34. Dasgupta TP, Smith JN. Reactions of S-nitrosothiols with L-ascorbic acid in aqueous solution. Nitric Oxide, Pt D 2002:219-229.

35. Barrett J, Debenham DF, Glauser J. Electronic Spectrum and Photolysis of S-Nitrosotoluene-AlphaThiol. Chem Comm 1965:248-249.

36. Williams DLH. The chemistry of S-nitrosothiols. Accounts Chem Res 1999;32:869-876.

37. Cazenave, J.; Mulvihill, J. Boston: Kluwer; 1993. The Role of Platelets in Blood-Biomaterial Interactions.

38. Oh BK, Robbins ME, Nablo BJ, Schoenfisch MH. Miniaturized glucose biosensor modified with a nitric oxide-releasing xerogel microarray. Biosens Bioelectron 2005;21:749-757. [PubMed: 16242614]

39. Mosmann T. Rapid Colorimetric Assay for Cellular Growth and Survival - Application to Proliferation and Cyto-Toxicity Assays. J Immunol Methods 1983;65:55-63. [PubMed: 6606682]

40. Gupta R, Kumar A. Bioactive materials for biomedical applications using sol-gel technology. Biomed Mater 2008;3034005 
41. Marxer SM, Rothrock AR, Nablo BJ, Robbins ME, Schoenfisch MH. Preparation of nitric oxide (NO)-releasing sol-gels for biomaterial applications. Chem Mater 2003;15:4193-4199.

42. Dicks AP, Swift HR, Williams DLH, Butler AR, AlSadoni HH, Cox BG. Identification of Cu+ as the effective reagent in nitric oxide formation from S-nitrosothiols (RSNO). J Chem Soc, Perkin Trans 1996;2:481-487.

43. Hwang S, Meyerhoff ME. Polyurethane with tethered copper(II)-cyclen complex: Preparation, characterization and catalytic generation of nitric oxide from S-nitrosothiols. Biomaterials 2008;29:2443-2452. [PubMed: 18314189]

44. Crichton RR, Pierre JL. Old iron, young copper: From Mars to Venus. Biometals 2001;14:99-112. [PubMed: 11508852]

45. Walshe JM. Wilson's disease: the importance of measuring serum caeruloplasmin nonimmunologically. Ann Clin Biochem 2003;40:115-121. [PubMed: 12662398]

46. O'Halloran TV, Culotta VC. Metallochaperones, an intracellular shuttle service for metal ions. J Biol Chem 2000;275:25057-25060. [PubMed: 10816601]

47. Valko M, Morris H, Cronin MTD. Metals, toxicity and oxidative stress. Curr Med Chem 2005;12:1161-1208. [PubMed: 15892631]

48. Dicks AP, Williams DLH. Generation of nitric oxide from S-nitrosothiols using protein-bound $\mathrm{Cu} 2$ + sources. Chem Biol 1996;3:655-659. [PubMed: 8807899]

49. Robbins ME, Hopper ED, Schoenfisch MH. Synthesis and characterization of nitric oxide-releasing sol-gel microarrays. Langmuir 2004;20:10296-10302. [PubMed: 15518528]

50. Nablo BJ, Schoenfisch MH. Poly(vinyl chloride)-coated sol-gels for studying the effects of nitric oxide release on bacterial adhesion. Biomacromolecules 2004;5:2034-2041. [PubMed: 15360321]

51. Nablo BJ, Chen TY, Schoenfisch MH. Sol-gel derived nitric-oxide releasing materials that reduce bacterial adhesion. J Am Chem Soc 2001;123:9712-9713. [PubMed: 11572708]

52. Nablo BJ, Schoenfisch MH. Antibacterial properties of nitric oxide-releasing sol-gels. J Biomed Mater Res, Part A 2003;67A:1276-1283.

53. Dobmeier KP, Schoenfisch MH. Antibacterial properties of nitric oxide-releasing sol-gel microarrays. Biomacromolecules 2004;5:2493-2495. [PubMed: 15530068]

54. Gristina AG. Biomaterial-centered infection: Microbial adhesion versus tissue integration. Science 1987;237:1588-1595. [PubMed: 3629258]

55. Poelstra KA, Barekzi NA, Rediske AM, Felts AG, Slunt JB, Grainger DW. Prophylactic treatment of gram-positive and gram-negative abdominal implant infections using locally delivered polyclonal antibodies. J Biomed Mater Res 2002;60:206-215. [PubMed: 11835177]

56. An YH, Friedman RJ. Concise review of mechanisms of bacterial adhesion to biomaterial surfaces. J Biomed Mater Res 1998;43:338-348. [PubMed: 9730073]

57. An, YH.; Dickinson, RB.; Doyle, RJ. Mechanisms of bacterial adhesion and pathogenesis of implant and tissue infections. In: An, YH.; Friedman, RJ., editors. Handbook of Bacterial Adhesion:Principles, Methods, and Applications. Totowa, NJ: Humana Press; 2000. p. 1-27.

58. Poelstra KA, van der Mei HC, Gottenbos B, Grainger DW, van Horn JR, Busscher HJ. Pooled human immunoglobulins reduce adhesion of Pseudomonas aeruginosa in a parallel plate flow chamber. $\mathrm{J}$ Biomed Mater Res 2000;51:224-232. [PubMed: 10825222]

59. Murugesan R, Hanley E, Albrecht RM, Oliver JA, Heintz JA, Lauer JL, et al. The effects of plasmaprocessing conditions on the morphology of adherent human blood platelets. J Appl Phys 2008;103

60. Goodman SL. Sheep, pig, and human platelet-material interactions with model cardiovascular biomaterials. J Biomed Mater Res 1999;45:240-250. [PubMed: 10397982]

61. Werner C, Maitz MF, Sperling C. Current strategies towards hemocompatible coatings. J Mater Chem 2007; 17:3376-3384.

62. Wink DA, Mitchell JB. Chemical biology of nitric oxide: Insights into regulatory, cytotoxic, and cytoprotective mechanisms of nitric oxide. Free Radical Biol Med 1998;25:434-456. [PubMed: 9741580]

63. Kroncke KD, Fehsel K, Kolb-Bachofen V. Nitric oxide: Cytotoxicity versus cytoprotection - How, why, when, and where? Nitric Oxide-Biol Chem 1997;1:107-120. 


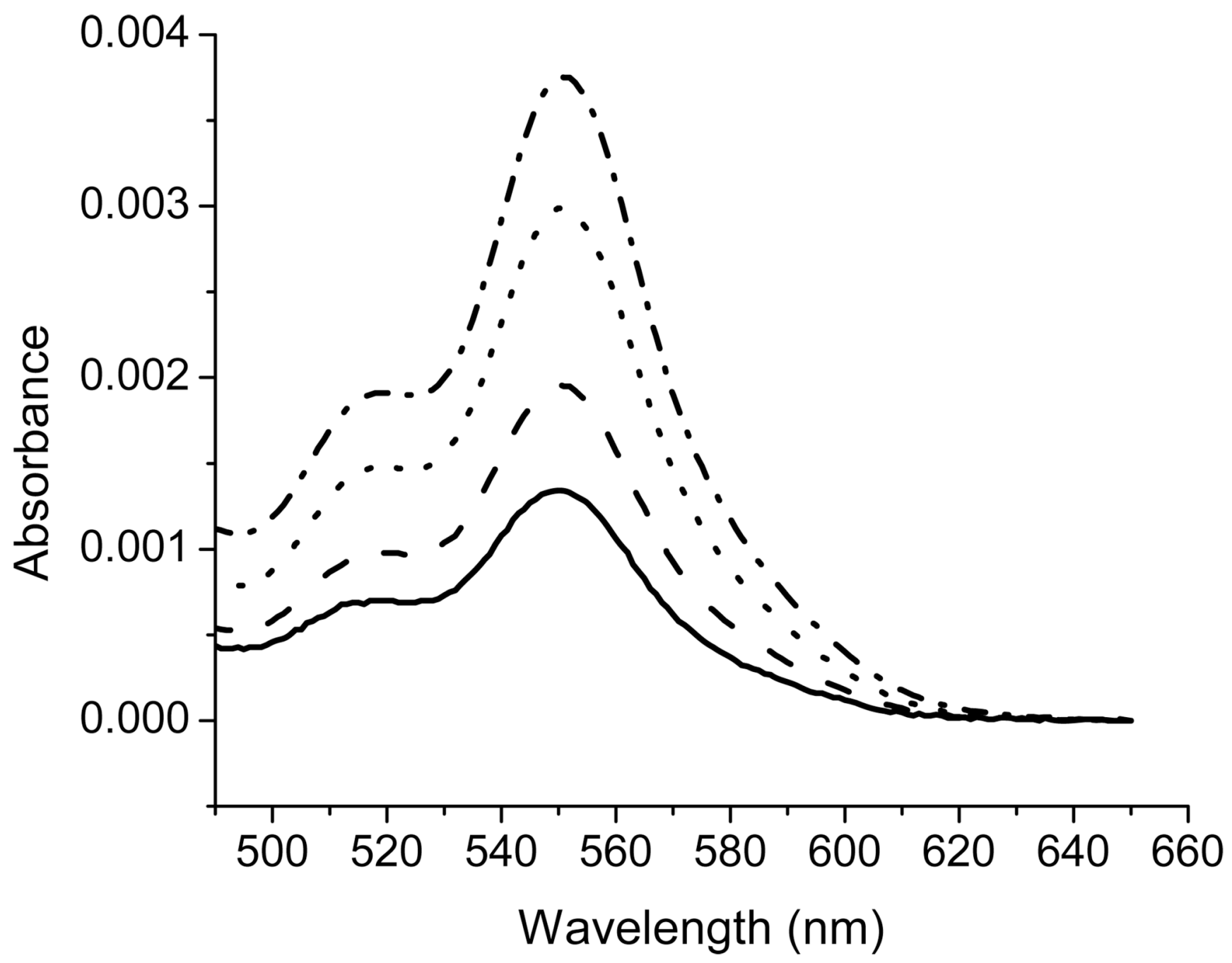

Fig. 1.

Absorbance spectra of RSNO-modified xerogels comprised of (-) 20\% MPTMS; (--) 40\% MPTMS; (...) 60\% MPTMS; and (-.-) 80\% MPTMS (v:v total silane, balance MTMOS). Baseline subtracted spectra were normalized to the average pathlength (film thickness) of each respective film. 

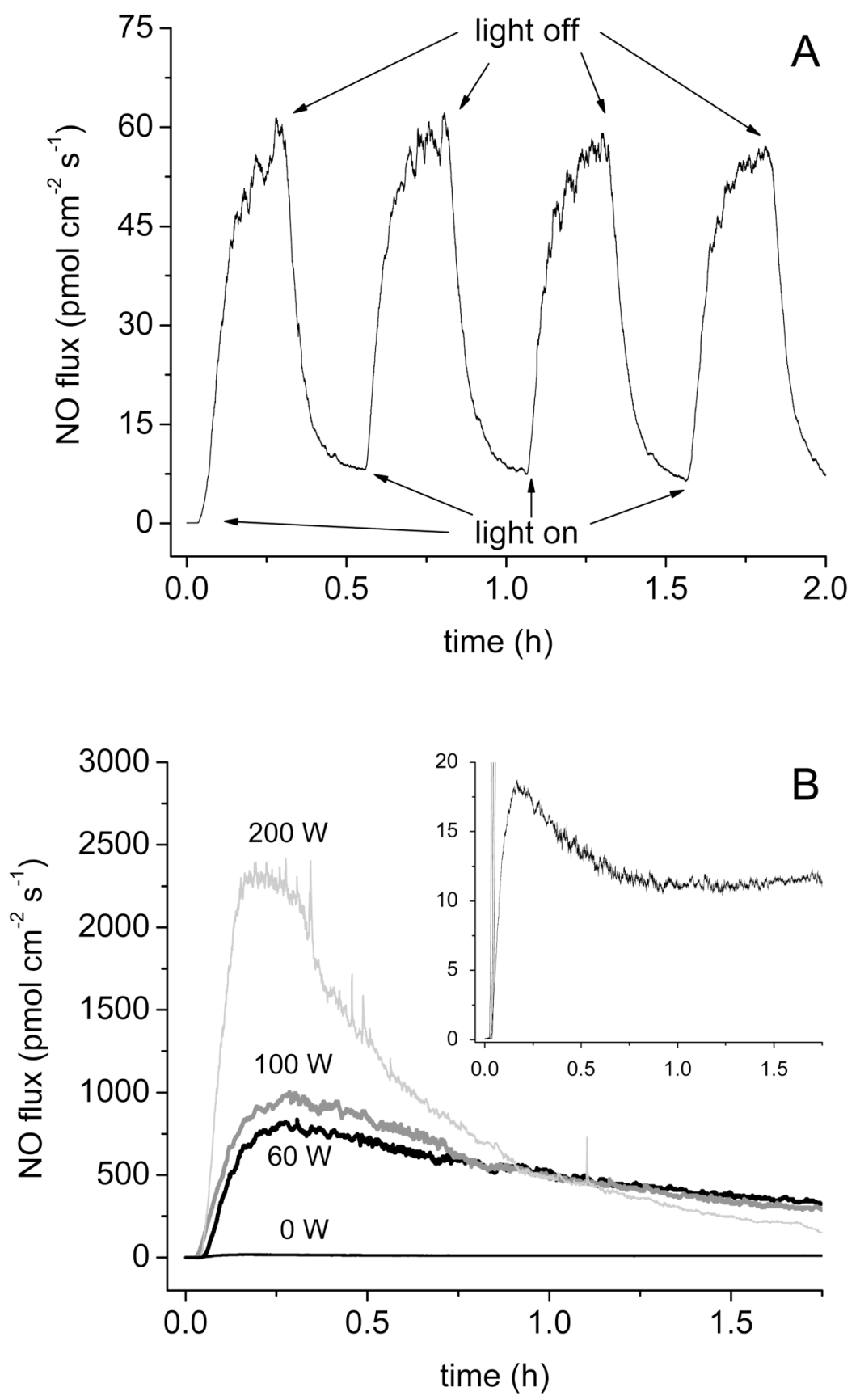

Fig. 2.

(A) On/off NO release behavior of RSNO-modified 20\% MPTMS (v:v total silane, balance MTMOS) xerogel as a function of light irradiation $\left(60 \mathrm{~W}\right.$ light source at $\left.0{ }^{\circ} \mathrm{C}\right)$.

(B) Nitric oxide flux from RSNO-modified 80\% MPTMS (v:v total silane, balance MTMOS) xerogels irradiated with 0, 60,100, and $200 \mathrm{~W}$ at $0{ }^{\circ} \mathrm{C}$. [Inset: Enlarged view of NO flux without irradiation] 


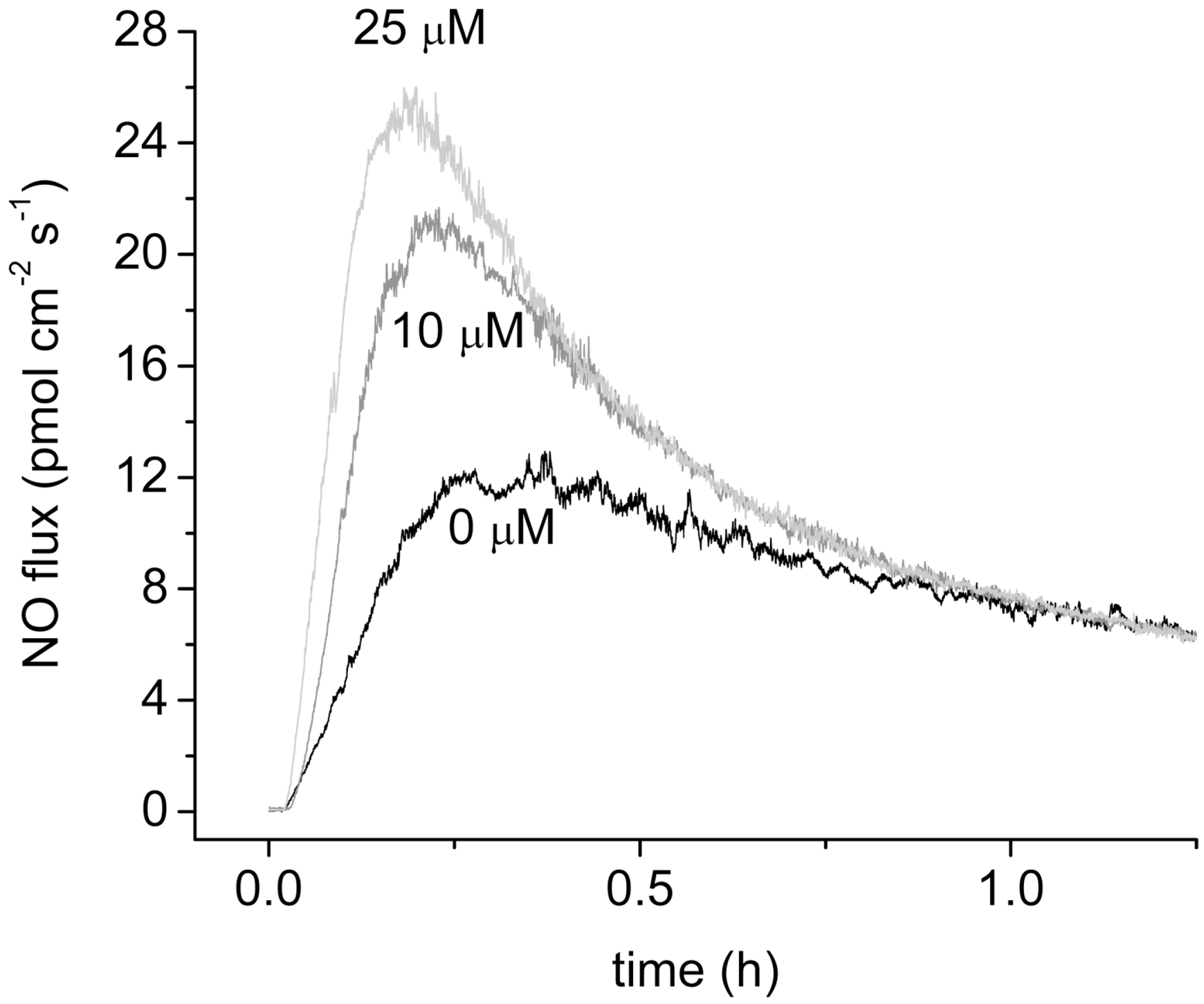

Fig 3.

Nitric oxide flux from RSNO-modified 20\% MPTMS (v:v total silane, balance MTMOS) films in 0,10 , and $25 \mu \mathrm{M} \mathrm{CuBr}_{2} / \mathrm{PBS}$ solution at $0{ }^{\circ} \mathrm{C}$. (Note: $0 \mu \mathrm{M} \mathrm{CuBr}_{2}$ is $100 \mu \mathrm{M}$ DTPA (pH 7.4 PBS)) 

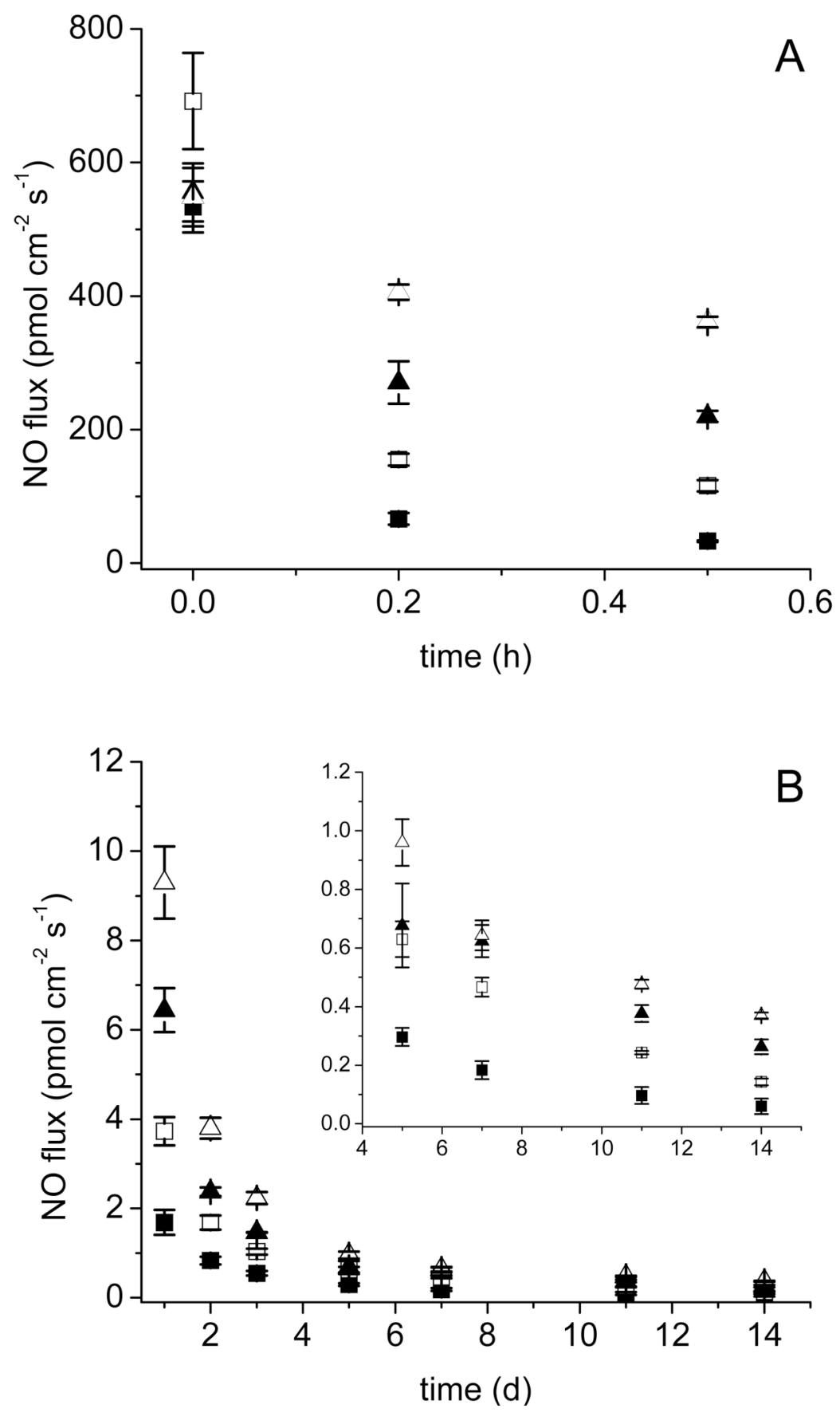

Fig 4.

Nitric oxide flux from RSNO-modified xerogels in $37{ }^{\circ} \mathrm{C} 100 \mu \mathrm{M}$ DTPA (pH 7.4 PBS). Data

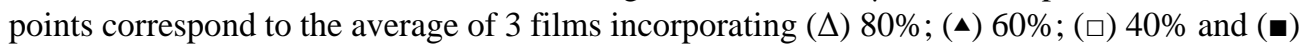
20\% MPTMS (v:v total silane, balance MTMOS). (A) Initial NO flux during the first $30 \mathrm{~min}$ of immersion. (B) Nitric oxide flux from 1-14 d. [Inset: Enlarged view of 5-14 d NO release.] 


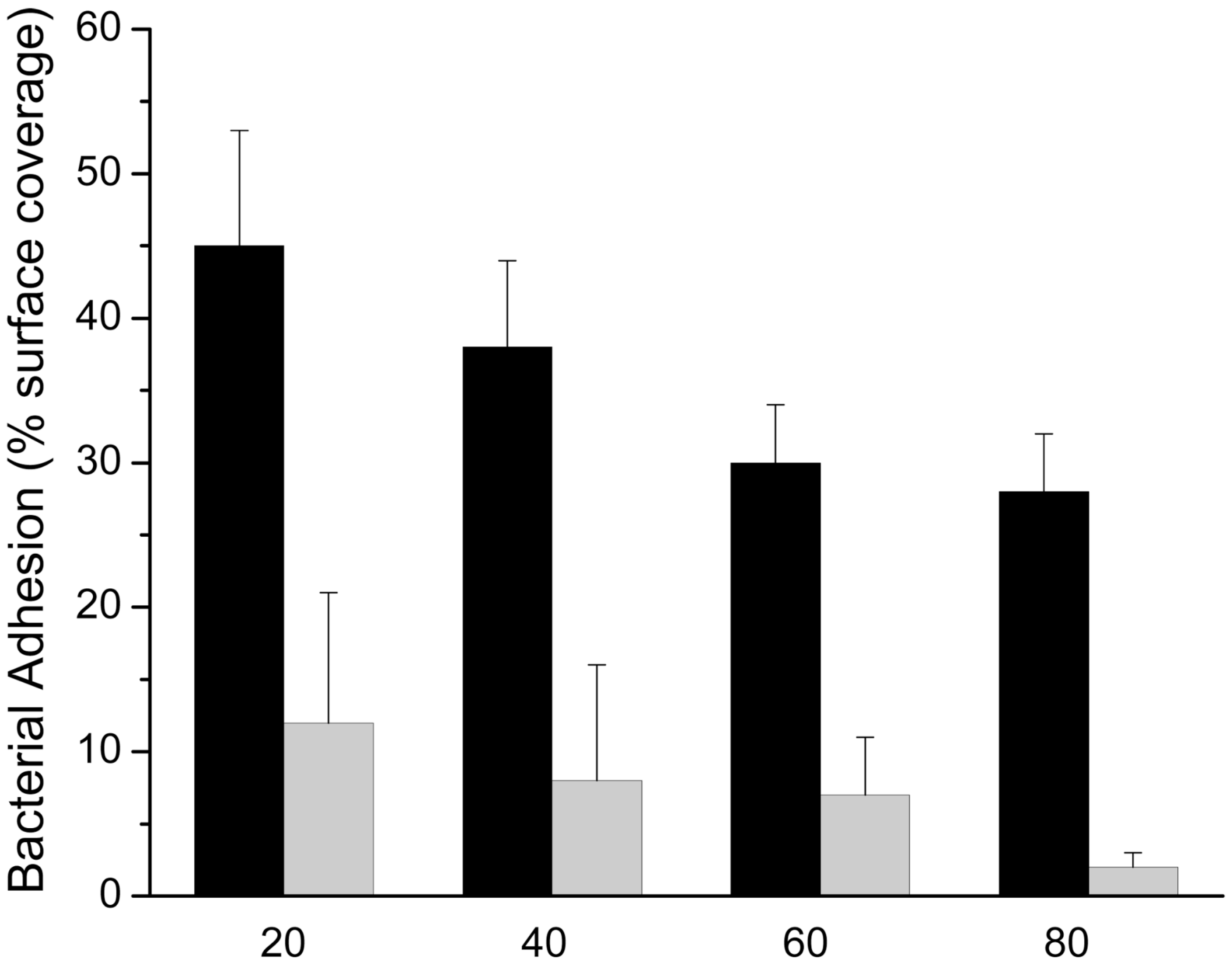

\section{\% MPTMS (v:v total silane, balance MTMOS)}

Fig 5.

P. aeruginosa adhesion to control (dark) and RSNO-modified (light gray) MPTMS/MTMOS xerogels. Bacterial adhesion reported as percent surface coverage. 

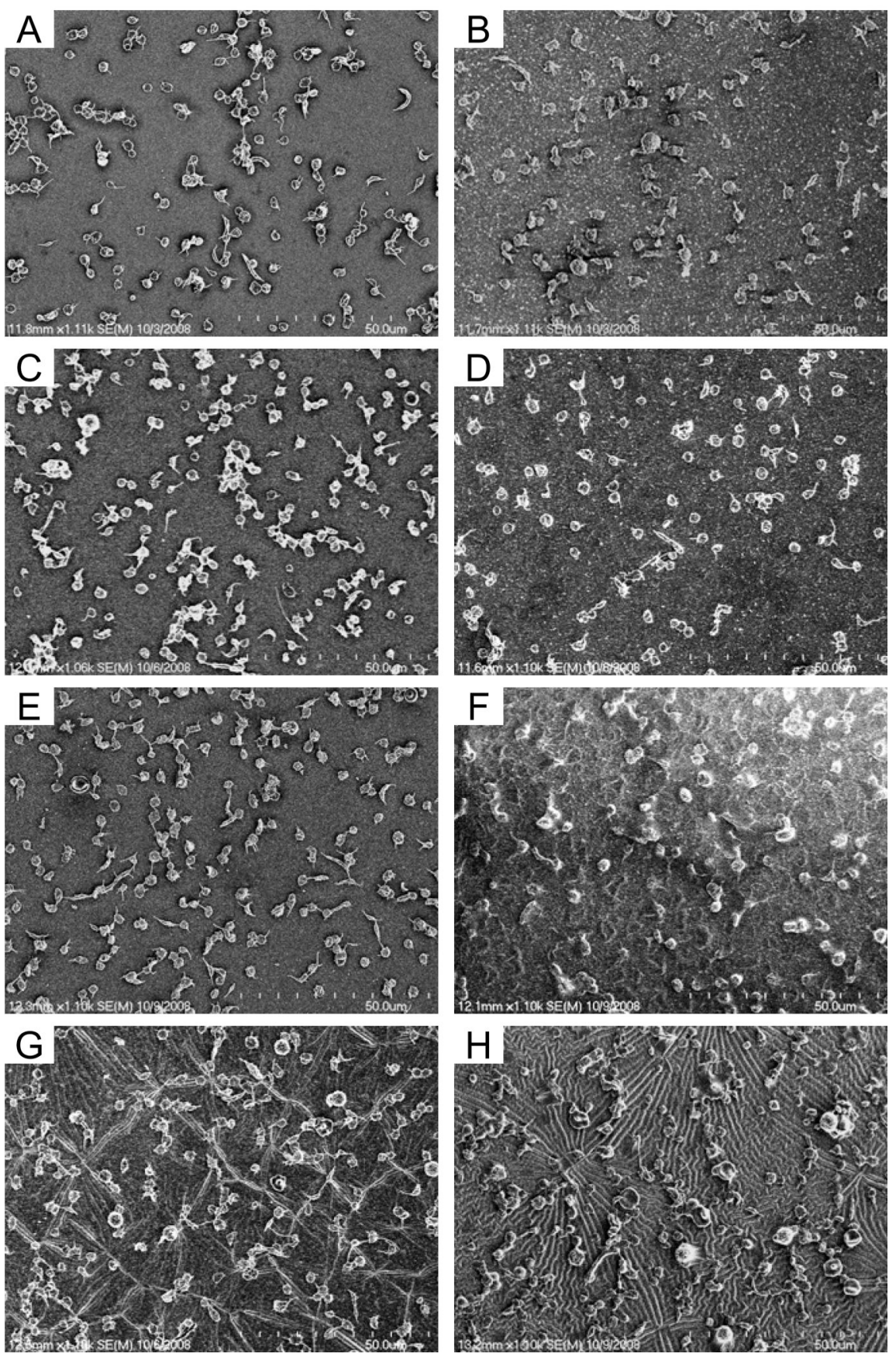

Fig. 6.

Representative scanning electron microscopy (SEM) images of platelet adhesion to (A,C,E,G) control and (B,D,F,H) RSNO-modified xerogels. 3-Mercaptopropyltrimethoxysilane (v:v total silane, balance MTMOS) xerogel compositions: (A,B) 20\%, (C,D) 40\%, (E,F) 60\%, and (G,H) $80 \%$. Note the enhanced surface roughness of the $80 \%$ composition $(\mathrm{G}, \mathrm{H})$. 


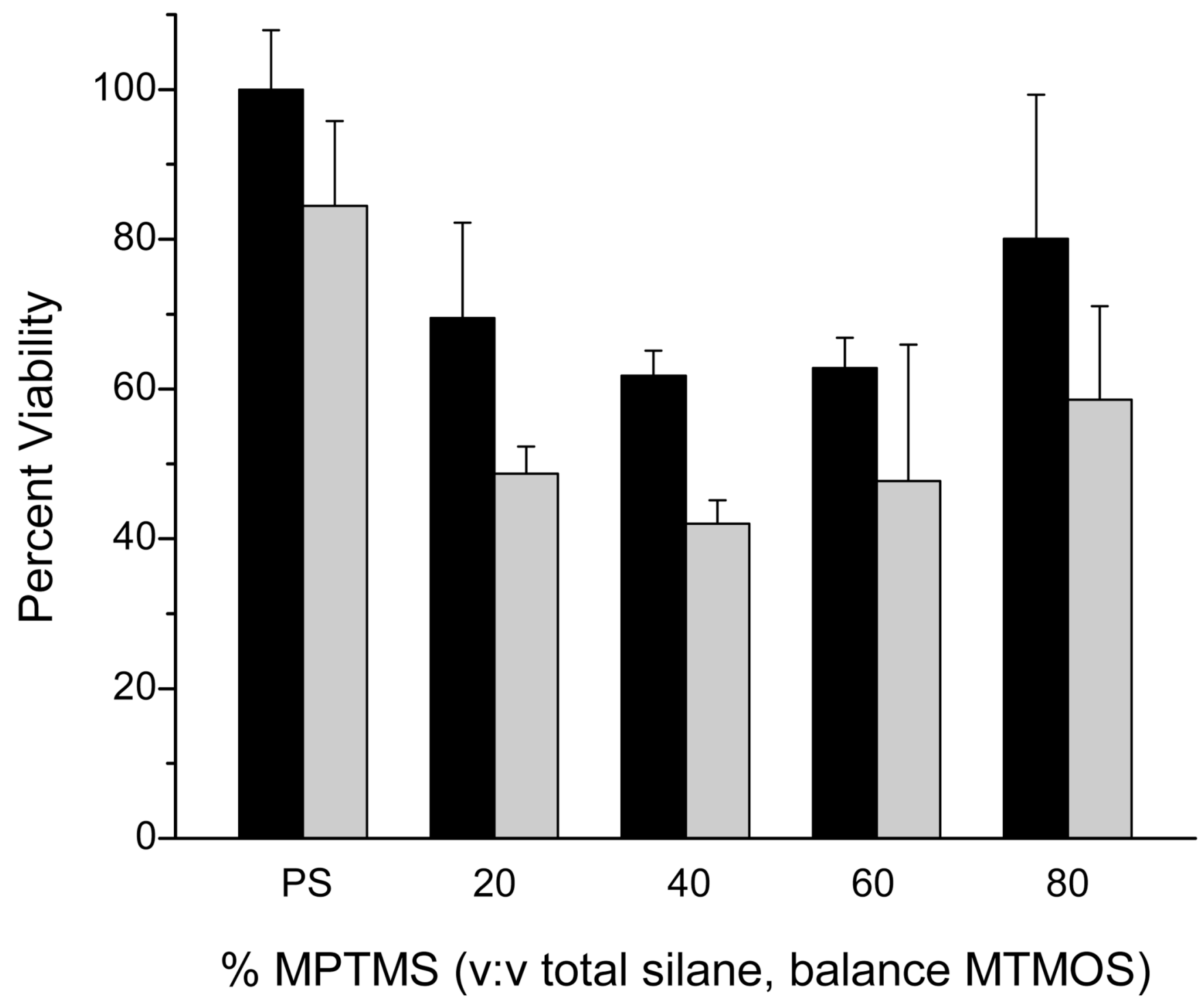

Fig. 7.

Viability of L929 Mouse fibroblast cells on polystyrene tissue culture wells (PS), control (dark), and RSNO-modified (light gray) MPTMS/MTMOS xerogels after $24 \mathrm{~h}$. Polystyrene tissue culture wells were either untreated (dark) or exposed to nitrosating conditions (light gray). 
Table 1

Total NO stored in RSNO-modified MPTMS/MTMOS xerogels

\begin{tabular}{cc}
\hline \% MPTMS $^{\boldsymbol{a}}$ & ${\text { Total NO released }\left(\boldsymbol{\mu m o l ~ m g}^{-\mathbf{1}}\right)^{\boldsymbol{b}}}$ \\
\hline 20 & $0.47 \pm 0.13$ \\
40 & $0.68 \pm 0.07$ \\
60 & $0.81 \pm 0.03$ \\
80 & $1.31 \pm 0.07$ \\
\hline
\end{tabular}

\footnotetext{
${ }^{a}$ Balance MTMOS, (v:v total silane)

${ }^{b}$ Average from $\mathrm{n}=3$, normalized to average mass of resulting xerogel
} 
Table 2

Contact angles of control and RSNO-modified MPTMS/MTMOS xerogels

\begin{tabular}{ccc}
\hline & \multicolumn{2}{c}{ Contact angle (deg) $\boldsymbol{b}$} \\
\cline { 2 - 3 } \% MPTMS $^{\boldsymbol{a}}$ & control & RSNO-modified \\
\hline 20 & $77 \pm 1$ & $67 \pm 3$ \\
40 & $73 \pm 2$ & $58 \pm 2$ \\
60 & $58 \pm 3$ & $51 \pm 1$ \\
80 & $48 \pm 2$ & $44 \pm 4$ \\
\hline
\end{tabular}

${ }^{a}$ Balance MTMOS, (v:v total silane)

${ }^{b}$ Sessile drop method, $\mathrm{H}_{2} \mathrm{O}$. Average from $\mathrm{n}=3$ 
Table 3

Amount of activated platelets adhered to control and RSNO-modified MPTMS/MTMOS xerogels.

\begin{tabular}{|c|c|c|}
\hline \multirow[b]{2}{*}{$\%$ MPTMS $^{a}$} & \multicolumn{2}{|c|}{ Adhered activated $^{b}$ platelets $^{c}$} \\
\hline & control & RSNO-modified \\
\hline 20 & $129 \pm 62$ & $106 \pm 17$ \\
\hline 40 & $210 \pm 6$ & $111 \pm 4$ \\
\hline 60 & $163 \pm 49$ & $79 \pm 8$ \\
\hline 80 & $205 \pm 64$ & $149 \pm 8$ \\
\hline \multicolumn{3}{|c|}{${ }^{a}$ Balance MTMOS, (v:v total silane) } \\
\hline \multicolumn{3}{|c|}{$b$ Defined as dendritic or fully spread morphology } \\
\hline
\end{tabular}

